\title{
Inter-disciplinary Approach Ought to Periodontitis and Type 1 Diabetes Mellitus in India
}

\section{Saurabh P. Kakade* and Khushboo Thakkar}

Public Health Dentistry, Dr.D.Y.Patil Dental College and Hospital, India

*Corresponding author: Saurabh P. Kakade, Public Health Dentistry, Dr.D.Y.Patil Dental College and Hospital, Pimpri, Pune- 411018, Maharashtra, India, Tel: +919766071333; E-mail: saurabh.kakade17@gmail.com

Rec date: Apr 17, 2014, Acc date: May 26, 2014, Pub date: June 01, 2014

Copyright: ( 2014 Kakade SP, et al. This is an open-access article distributed under the terms of the Creative Commons Attribution License, which permits unrestricted use, distribution, and reproduction in any medium, provided the original author and source are credited.

\section{Letter to the Editor}

Oral health of diabetic individuals has been the subject of many studies in recent years. Periodontal disease is identified as the sixth complication of diabetes mellitus. Periodontitis is one of the numerous complications of Type 2 diabetes mellitus but is less clearly recognized in Type 1 Diabetes, this association is less straightforward [1,2]. While extensive work has been done to determine and document the increasing incidence of Type 2 diabetes worldwide, comparatively less attention has been focused on the prevalence of Type 1 diabetes, especially in the developing world. In diabetic subjects with periodontitis, those with $\mathrm{HbAlc}$ levels over $8 \%$ had crevicular fluid levels of interleukin-1 beta (IL-1b) almost twice as high as subjects with $\mathrm{HbA1c}$ levels $<8 \%$. The net effect of these host defense alterations in diabetes is an increase in periodontal inflammation, attachment loss, and bone loss. The increased levels of periodontal attachment and bone loss seen in diabetic individuals may be associated with the alterations in connective tissue metabolism that uncouple the resorptive and formative responses [3].

The prevalence of Type 1 diabetes has been studied by various methods, including surveys, national or central registries, school records and hospital records, in various age groups. It varies from 0.09 per 1000 in China, to 0.83-2.23 in Scandinavia and 3.40 in United Kingdom. Incidence studies are available from many countries and reveal rates ranging from 36.5/100,000 in Finland and 36.6/100,000 in Sardinia (Italy) to $0.1-4.6 / 100,000$ in China and $0.4 / 100,000$ in Thailand. The incidence is low in all Asian countries studied viz. Japan, China, Hong Kong, Pakistan and Thailand. In the Indian state of Karnataka, Type 1 diabetes registry reports an incidence of $3.7 / 100,000$ in boys and 4.0/100,000 in girls, over 13 years of data collection. The incidence of Type 1 diabetes has been reported as $10.5 / 100,000$ in a population based study carried out in 1996 in urban Chennai. Previous studies have revealed a prevalence rate of 1.6 to 10.1 per 100000 population in India [2].

Periodontal destruction starts early in life and becomes more prominent as children become adolescents [1]. Type 1 diabetic individuals may have an increased susceptibility to periodontal disease; the probability of detecting an increased prevalence in patients with Type 1 diabetes is more controversial. In Type 1 diabetic children, the prevalence of gingivitis was greater than in non-diabetic children with similar plaque levels [4]. Twice as many sites had gingival inflammation in children with diabetes compared to nondiabetic control children with similar plaque levels. Poor metabolic control can increase the severity of gingival inflammation in diabetic children, whereas improvement in glycemic control may be associated with decreased gingival inflammation [4]. Type 1 diabetic individuals with poor metabolic control over the preceding 2 to 5 years had a significantly greater prevalence of deep probing depths and advanced attachment loss than subjects with good glycemic control. In type1 diabetic adults, overall degree of gingival inflammation was similar between diabetic individuals as a whole and non-diabetic individuals with similar plaque accumulation [4]. India being the diabetic capital of the world and since there is a steady rise of type 1 diabetics, the need arises for inter-disciplinary action to join hands in tackling periodontal issues of Type 1 diabetic individuals in India which is the area underserved.

In India biggest lacunae is lack of knowledge regarding information about oral health care in diabetic individuals, which may further highlight the need for providing more information about oral health which can be dissipated through educational campaigns, national forums, continuing medical/dental education programs and through the various diabetic associations in India. First step towards interdisciplinary approach can be through assessing periodontal diseases in atleast diabetic children which can be suggested and introduced in the Indian general health care system through national and international forums and collaborations. Diabetologists and allied health professionals should emphasize the importance of oral health and dental care in the early stage of the diseases, and its integration in the general care of these patients. From this point of view, the call for an inter-disciplinary approach between dental, medical and allied health colleagues is justified.

\section{References}

1. Chávarry NG, Vettore MV, Sansone C, Sheiham A (2009) The relationship between diabetes mellitus and destructive periodontal disease: a meta-analysis. Oral Health Prev Dent 7: 107-127.

2. Kalra S, Kalra B, Sharma A (2010) Prevalence of Type 1 diabetes mellitus in Karnal district, Haryana state, India. Diabetol Metab Syndr 2: 14.

3. American Diabetes Association (2004) Diagnosis and classification of diabetes mellitus. Diabetes Care 27 Suppl 1: S5-5S10.

4. Mealey BL, Oates TW; American Academy of Periodontology (2006) Diabetes mellitus and periodontal diseases. J Periodontol 77: 1289-1303. 